www.jmscr.igmpublication.org

Impact Factor 5.84

Index Copernicus Value: 83.27

ISSN (e)-2347-176x ISSN (p) 2455-0450

crossref DOI: _https://dx.doi.org/10.18535/jmscr/v5i8.211

Journal Of Medical Science And Clinical Research

\title{
The Study of Effectiveness of Analgesia with Fascia Iliaca Compartment Block (FICB) for Positioning during Spinal Anaesthesia and the Duration of Post-Operative Analgesia Using Bupivacaine in Patients with Proximal Fracture Femur
}

\author{
Authors \\ Dr Syeda Sana ${ }^{1}$, Dr Ramesh G. Pathak ${ }^{2}$, Dr Nazima Memon ${ }^{3}$ \\ ${ }^{1}$ Junior Resident, ${ }^{2}$ Professor and Head, ${ }^{3}$ Assistant Professor \\ Department of Anaesthesiology, Dr. Shankarrao Chavan Government Medical College, Nanded \\ Corresponding Author \\ Dr Ramesh G. Pathak \\ Professor and Head, Dept of Anaesthesiology, Dr. Shankarrao Chavan Govt Medical College, Nanded
}

\begin{abstract}
Introduction: Fracture neck of femur is a common occurrence especially in elderly population. This is accompanied by severe pain and discomfort. Fascia Iliaca Compartment Block (FICB) is traditionally used by many anesthetists for preoperative pain relief with excellent results. The purpose of this study was to determine efficacy of FICB, to determine analgesic effect of FICB for positioning during spinal anaesthesia and to determine its efficacy for post-operative analgesia.

Materials and Methods: A case control study for determining effectiveness of analgesia with fascia Iliaca compartment block (FICB) for positioning during spinal anaesthesia and the duration of post-operative analgesia was conducted at a tertiary care hospital situated in an urban area. Total 60 patients were enrolled in this study. Control group and interventional group both consisted of 30 patients each. The control group received $40 \mathrm{ml} \mathrm{NS}$ while interventional group received $0.25 \%$ bupivacaine $(38 \mathrm{ml})$ plus normal saline $0.9 \%(2 \mathrm{ml})$ making total $40 \mathrm{ml}$. Hemodynamic stability, VAS score, Pinprick sensation and quality of analgesia were compared in control and interventional group.

Results: Mean age of patients in control and interventional group was $55.6 \pm 12.25$ and $54.80 \pm 12.80$ respectively. The mean duration of surgery was $2.05 \pm 0.37$ and $2.08 \pm 0.42$ in control and interventional group. In control group all patients (100\%) had grade 0 analgesia while in interventional group 3 patients (10\%) had grade I analgesia and 27 patients (90\%) had grade 2 analgesia. There was a statistically significant difference in mean arterial pressure and heart rate during positioning at 30 minutes and control and intervention groups. There was statistically significant difference in VAS scores of these 2 groups from 30 minutes to 12 hours postoperatively. The difference between control and intervention groups for return of pinprick sensation was also found to be statistically significant.

Conclusion: FICB using $0.25 \%$ Bupivacaine is a rapid and effective method for positioning of patient and post-operative pain relief in patients undergoing surgery for fracture neck of femur under spinal anaesthesia.

Keywords: Fracture neck of femur, Fascia Iliaca Compartment Block, Bupivacaine, Post-operative analgesia.
\end{abstract}




\section{Introduction}

Fracture femur is a common injury in elderly patients. Fracture is a painful bone injury because the periosteum has the lowest pain threshold amongst the deep somatic structure ${ }^{[1]}$. It is well recognised that pain might be the cause of many undesirable effects on several physiological processes, especially in elderly patients who usually have limited physiological reserves. In geriatric patients, the effect of pain on the cardiovascular system may be detrimental (due to increased catecholamine release leading to tachycardia and hypertension). It seems that pain also negatively affects the immune system and delays the normal process of healing ${ }^{[2]}$.

Spinal anaesthesia is widely accepted anesthetic technique than general anaesthesia for internal fixation of femur fracture or replacement of femoral head. It has been demonstrated that Fascia Iliaca Compartment Block provides effective and safer analgesia for fracture femur when given preoperatively ${ }^{[3]}$. FICB was described for the first time in children in 1989 in a paper published by Dalens et al. FICB blocks femoral nerve and lateral cutaneous nerve of thigh, thereby providing effective and safer analgesia in hip fracture patients. The use of FICB just prior to spinal anaesthesia helps to relieve the pain associated with positioning for spinal anaesthesia and improve patient compliance ${ }^{[4]}$. It is not only effective for positioning but also provides postoperative analgesia after the effect of spinal anaesthesia weans off ${ }^{[5]}$. Thus we used FICB in the present study for optimal positioning of the patient with proximal femur fracture for spinal anaesthesia and also to assess post-operative pain relief.

The present study was designed to determine efficacy and success of FICB to provide analgesia for positioning for spinal anaesthesia and to determine and evaluate post-operative analgesia with bupivacaine.
Aims and Objectives

1. To determine efficacy and success of FICB in patients with fracture neck of femur.

2. To determine analgesia with FICB for positioning during spinal anaesthesia.

3. To determine post-operative analgesic effect of FICB in patients with fracture neck of femur.

\section{Material and Methods}

The present study was randomized, prospective, double blind case control study. It was carried out in a tertiary health care centre situated in an urban area over a period of 2 years. After obtaining Institutional ethical committee approval and informed written consent from the patients, 60 patients were enrolled in the study. The study population included patients of either gender, ASA grade I \& II between the age group of 18-80 years and undergoing surgery for proximal fracture femur under spinal anaesthesia. All these patients received FICB by landmark technique before spinal anaesthesia. The control group received $40 \mathrm{ml} \mathrm{NS}$ while interventional group received $0.25 \%$ bupivacaine $(38 \mathrm{ml})$ plus normal saline $0.9 \%$ (2ml) making total $40 \mathrm{ml}$. Hemodynamic stability, VAS score, Pinprick sensation and quality of analgesia were compared in control and interventional group.

\section{Inclusion criteria}

* Age 18-80 years of both sex

* ASA grade I \& II

* Patient posted for proximal fracture femur under spinal anaesthesia

\section{Exclusion criteria}

* Patient refusal

* Allergy to local anesthetics.

* Infection at local site of block

* Patients who received any analgesic within 8 hours of procedure.

* Any anatomical deformity at site of FICB (inguinal hernia, femur bypass

* surgery) 
* Hemodynamic Instability

* Contraindications for Spinal anaesthesia

Preoperative assessment and all routine investigations were done. On arrival of patient in operation room all patients were monitored with Pulse oximetry (Spo2), NIBP, heart rate and VAS score Prior to FICB and throughout the procedure Intravenous line was set up and an infusion of Ringer lactate solution was started and continued throughout the procedure.

\section{Technique of FICB}

The block was carried out as described by Landmark Technique described by Dalens et al after thorough explanation of the procedure to patient.

1) Single injection landmark approach was used for performing FICB. The patient was in supine position on operation table. Operative site was confirmed. Part of thigh where block was to be given was exposed. The operator stood by side of operative limb. Landmarks i.e. Anterior Superior Iliac Spine and pubic tubercle were identified by palpation. A line was drawn on skin from anterior superior iliac spine to pubic tubercle. It was divided in three equal parts. A point $1 \mathrm{~cm}$ below the junction of medial two thirds and lateral one third was marked. This was the site of drug injection. Aseptic cleaning and draping of area was done, ipsilateral femoral pulse was palpated at the level of planned injection site. The pulse should be palpable 1.5 to $2 \mathrm{~cm}$ medial to the intended injection point to ensure a safe distance from the femoral nerve to avoid femoral nerve involvement. Marked point was infiltrated with $2 \%$ lidocaine $(2 \mathrm{ml})$ Using $21 \mathrm{~g}$ needle skin was pierced at 90 degrees. The needle was further advanced till two pops were felt. The first pop felt was of fascia lata and second pop felt was of fascia iliaca. Drug solution was given using $10 \mathrm{ml}$ syringe after negative aspiration. There was no resistance to injection. If there was resistance, the needle tip was likely to be within iliacus muscle. In that case the needle was slightly withdrawn until the injection was easy. There should be no pain or paraesthesia on injection. The site of injection was compressed with cotton swab. During the procedure and thereafter patient was observed vigilantly for any complication of block and for toxicity of the drug injected. Following precautions were taken during conduct of block to prevent deleterious effects: (1) Repeated aspiration before injection to prevent intravascular spread of drug. (2) Injection was to be stopped immediately if early signs of toxicity appeared.

The following parameters were studied

(1) Haemodynamic variables pulse rate and blood pressure (NIBP) were recorded at 30 minutes.

(2) Visual Analogue Scale score was noted at 30 minutes while positioning for spinal anaesthesia.

VAS score was recorded on $100 \mathrm{~mm}$ line marked from 0 to 100 in which 0 indicated no pain and 100 indicated severe pain. Patients were explained about VAS score.0 - No pain and 100 - severe pain Visual Analog Scale (VAS) for pain severity measurement. Rating was done as described by Jensen et al.

\section{VAS}

0 to $4 \mathrm{~mm}$ - no pain

$05-44 \mathrm{~mm}$ - mild pain

45-74mm - moderate pain

75-100mm - severe pain

c) Pinprick sensation was noted in anterior and lateral aspect of thigh at 30 minutes. According to response to pin prick sensory blockade was rated as follows.

Grade 0 - Sharp pin prick felt

Grade 1 - Dull sensation felt

Grade 2 - No sensation felt

A successful block was defined as absence of pinprick sensation in anterior and lateral aspect of thigh.

\section{Observation and Results}

The study comprised of 60 patients of fracture neck of femur undergoing surgery under spinal anaesthesia in whom FICB was given. Out of 60 patients 28 were males and 32 were females with a $\mathrm{M}$ : F ratio being $1: 1.14$. 


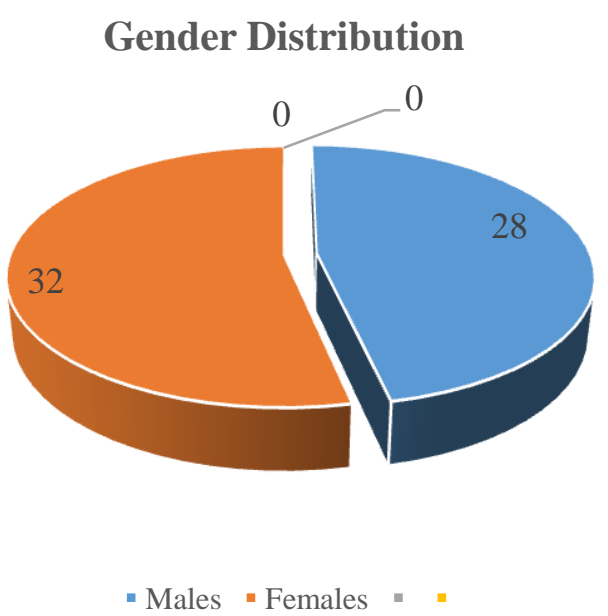

Figure 1 Gender Distribution of the studied cases. The patients belonging to ASA Grade I and II were included in this study. Being an exclusion criteria ASA Grade III or higher were excluded from the study.

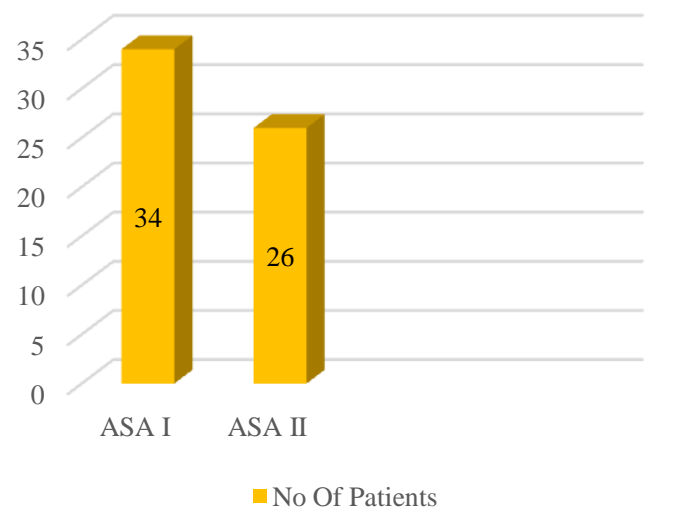

Figure 2: ASA grades of the studied cases.

The demographic characteristics of the patients showed that there was a female preponderance.
Majority of the patients belonged to ASA Grade 1 (34/60) and 26 patients belonged to ASA grade II. There was a female preponderance. Mean age of the patients in control and intervention group was found to be $55.6 \pm 12.25$ years and $54.80 \pm 12.80$ years respectively. The duration of surgery was $2.05 \pm 0.37$ and $2.08 \pm 0.42$ hours in control and intervention groups respectively.

Table 1: Demographic characteristics of the studied cases.

\begin{tabular}{|l|c|c|}
\hline \multicolumn{1}{|c|}{$\begin{array}{c}\text { Control } \\
\text { Group }\end{array}$} & $\begin{array}{c}\text { Intervention } \\
\text { Group }\end{array}$ \\
\hline $\begin{array}{l}\text { Mean Age of the } \\
\text { patient }\end{array}$ & $55.6 \pm 12.25$ & $54.80 \pm 12.80$ \\
\hline $\begin{array}{l}\text { Sex distribution } \\
\text { (M/F) }\end{array}$ & $15 / 15$ & $13 / 17$ \\
\hline ASA grading I / II & $16 / 14$ & $18 / 12$ \\
\hline Duration of surgery & $2.05 \pm 0.37$ & $2.08 \pm 0.42$ \\
\hline
\end{tabular}

The analysis of grades of analgesia in control and interventions groups revealed that most of the patients (90\%) in intervention group had Grade 2 analgesia (No sensation) and all the patients $(100 \%)$ in control group had Grade 0 analgesia (pain sensation present). The difference in level of analgesia was found to be statistically significant implying that there was significant difference in grade of analgesia for spinal positioning in patients receiving FICB.

Table 2: Grade of Analgesia (by pinprick sensation) for spinalpositioning at 30 minutes after FICB

\begin{tabular}{|l|c|c|c|c|}
\hline \multicolumn{2}{|c|}{ Pinprick Sensation } & & Grade 2 & P value \\
& $\begin{array}{c}\text { Grade 0 } \\
\text { Pain } \\
\text { Sensation }\end{array}$ & $\begin{array}{c}\text { Grade1 } \\
\text { Dull } \\
\text { Sensation }\end{array}$ & Sensation & \\
\hline Control group & $30(100 \%)$ & 0 & 0 & P $<0.05$ \\
\hline Intervention group & 0 & 03 & 27 & (Significant) \\
\end{tabular}




\section{JMSCR Vol||05||Issue||08||Page 27260-27267||August}

Figure 3: Quality of analgesia in studied cases.

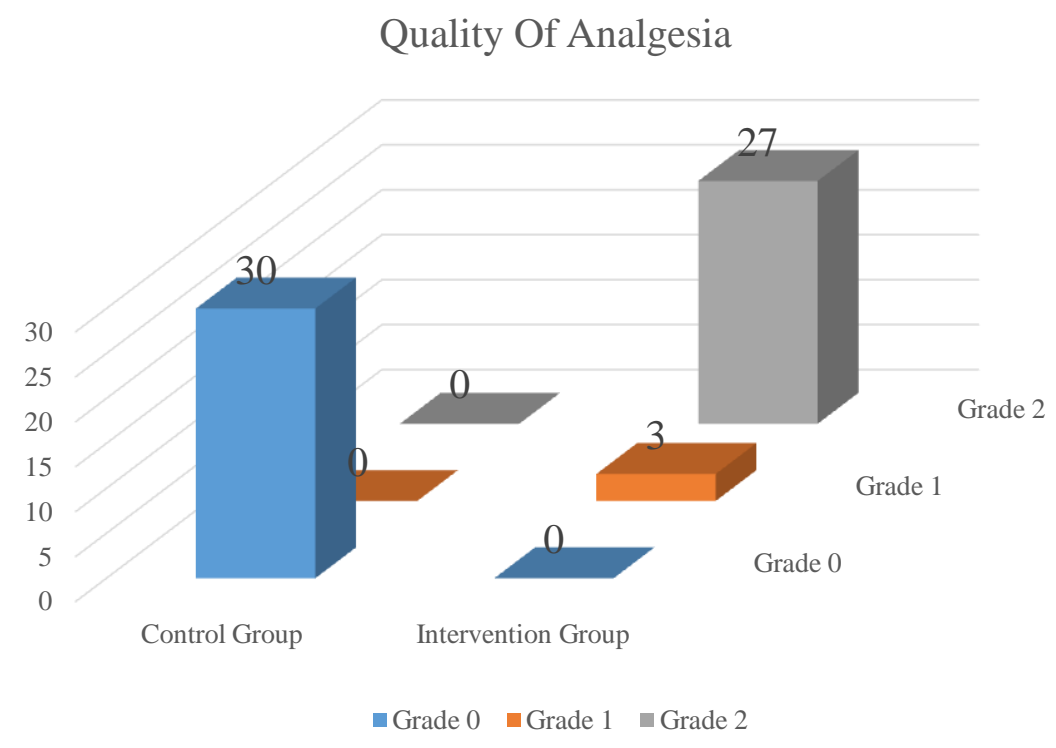

The analysis of vital parameters of the patients in control and intervention groups revealed that there was statistically significant difference between control and intervention groups in mean arterial pressure and heart rate during positioning at 30 minutes. The difference in Baseline Mean arterial pressure, Heart rate and SPO2 (Baseline as well as during positioning at 30 minutes) was not found to be statistically significant.

Table 3: Comparison of vital parameters between control and interventional Groups

\begin{tabular}{|c|c|c|c|}
\hline & $\begin{array}{l}\text { Control group } \\
\qquad(\mathrm{n}=30)\end{array}$ & $\begin{array}{l}\text { Interventional group } \\
\qquad(\mathrm{n}=\mathbf{3 0})\end{array}$ & $\begin{array}{c}\text { P value } \\
\text { Significant/ } \\
\text { Not Significant }\end{array}$ \\
\hline Baseline MAP mm Hg & $90.12 \pm 12.56$ & $91.48 \pm 09.50$ & Not Significant \\
\hline $\begin{array}{l}\text { MAP during positioning at } \\
\mathbf{3 0} \mathrm{min} \mathbf{m m} \mathbf{H g}\end{array}$ & $98.12 \pm 11.06$ & $90.18 \pm 08.40$ & Significant \\
\hline Baseline HR per minute & $80.6 \pm 12.56$ & $81.8 \pm 13.03$ & Not Significant \\
\hline $\begin{array}{l}\text { HR during positioning at } 30 \\
\text { min } \mathrm{mm} \mathrm{Hg}\end{array}$ & $86.5 \pm 10.46$ & $80.2 \pm 12.12$ & Significant \\
\hline Baseline $\mathrm{SpO}^{2}(\%)$ & $99.02 \pm 7.42$ & $98.14 \pm 6.48$ & Not Significant \\
\hline $\begin{array}{l}\text { SpO }{ }^{2} \text { during positioning at } \\
30 \mathrm{~min} \mathrm{~mm} \mathrm{Hg}(\%)\end{array}$ & $98.23 \pm 4.44$ & $98.20 \pm 3.12$ & Not Significant \\
\hline
\end{tabular}

The analysis of mean VAS score in control and interventional group revealed that mean VAS score was significantly more in control group at 30 minutes, Rest of the time there was no statistically significant difference in VAS scores due to effect of spinal anaesthesia in control as well as intervention groups.

Table 4: Mean VAS score in control and interventional group.

\begin{tabular}{|l|c|c|c|c|c|c|}
\hline $\begin{array}{l}\text { Groups } \\
\begin{array}{l}\text { Control group } \\
(\mathbf{n = 3 0})\end{array}\end{array}$ & $\mathbf{0}$ min & $\mathbf{3 0 m i n}$ & $\mathbf{2 h r s .}$ & $\mathbf{4}$ hrs. & $\mathbf{8 h r s .}$ & $\mathbf{1 2}$ hrs. \\
\hline $\begin{array}{l}\text { Interventional group } \\
(\mathbf{n = 3 0})\end{array}$ & $80 \pm 3.16$ & $90 \pm 3.25$ & $40 \pm 4.11$ & $50 \pm 5.10$ & $90 \pm 1.11$ & $90 \pm 1.13$ \\
\hline
\end{tabular}




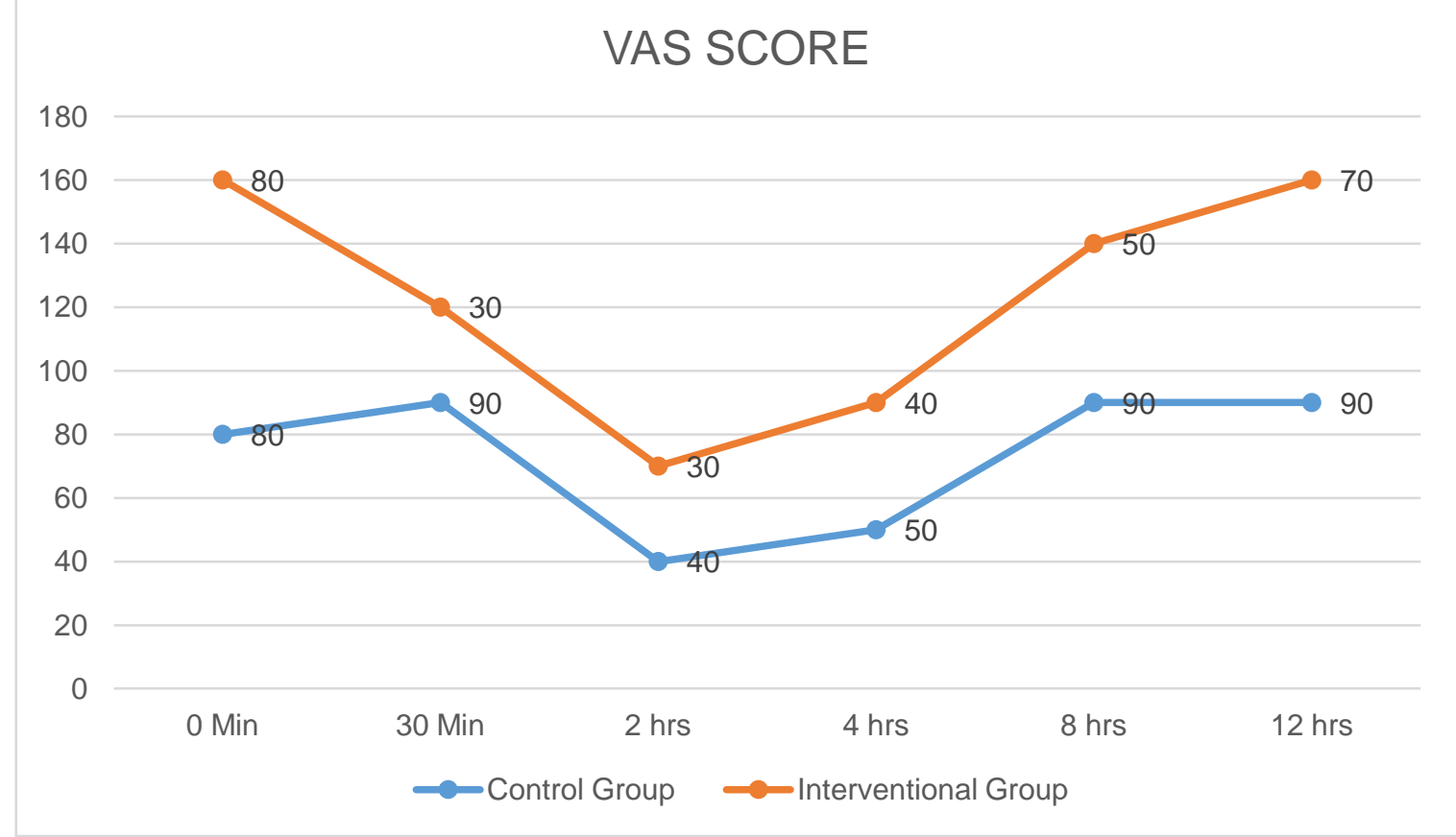

Figure 4: VAS Scores in the studied cases.

The time required for return of pinprick sensation on operated limb was found to be $3.36 \pm 0.76 \mathrm{hrs}$ in control group and $7.14 \pm 3.20 \mathrm{hrs}$ in interventional group. The difference was found to be statistically significant $(\mathrm{P}<0.05)$.

Table 5: Return of Pinprick sensation on operated limb (time in hours).

\begin{tabular}{|c|c|c|c|}
\hline Groups & $\begin{array}{l}\text { Control group } \\
\qquad(\mathrm{n}=\mathbf{3 0})\end{array}$ & $\begin{array}{l}\text { Interventional group } \\
\qquad(\mathrm{n}=\mathbf{3 0})\end{array}$ & $\begin{array}{c}\text { P value } \\
\text { Significant/ } \\
\text { Not Significant }\end{array}$ \\
\hline Mean \pm SD (hrs.) & $3.36 \pm 0.76 \mathrm{hrs}$ & $7.14 \pm 3.20 \mathrm{hrs}$ & $\mathrm{P}<0.05$ - significant \\
\hline
\end{tabular}

\section{Discussion}

Fascia iliaca compartment block (FICB) was first performed in 1989 in children and later on adults. It was mainly used to provide analgesia following surgical procedures in hip, femur, knee, treatment of burns on thigh and in pre-hospital treatment of fracture femur ${ }^{[6,7]}$. Single shot fascia ilaica block provides effective analgesia for positioning of the patient with proximal femur fracture during spinal anesthesia and also provides postoperative analgesia. It blocks two main lumbar plexus nerves femoral and lateral cutaneous nerve of thigh by central spread of local anesthetic ${ }^{[8]}$.

A fractured proximal femur is subjected to major muscle forces that can deform the thigh and angulate bone fragments. Therefore complete paralysis of all muscles acting on femur is mandatory for intraoperative realignment of fracture. Spinal anesthesia is widely used anesthetic technique for intertrochanteric nailing, replacement of head by Austin Moore prosthesis and putting proximal femur nail. The positioning of these patients to perform spinal anaesthesia is often problematic because even slight overriding of fracture is intensely painful. When considering the technique used to aid positioning for spinal block, Sandby-Thomas et al reported that the most frequently used agents were midazolam, ketamine, and propofol. Alternative agents were fentanyl, remifentanil, morphine, nitrous oxide, and sevoflurane whereas nerve blocks were used infrequently ${ }^{[9]}$.

The beneficial effect of FICB in patients with radiologically confirmed hip fractures is well known with several studies reporting a good outcome when compared to NSAIDS and 
alfentanil. FICB provides good pain relief for patients with femoral shaft fractures when used in pre-hospital care and is simple, easy to perform and requires less skill. Unlike FNB, FICB does not require the use of nerve stimulator which could cause additional pain to the patient due to quadriceps muscle contraction. Ghimire A et al concluded that Fascia iliaca compartment block provides better analgesia than femoral nerve block in terms of facilitating optimal positioning for subarachnoid block in patients undergoing proximal femoral fracture fixation procedure ${ }^{[10]}$.

All our patients were in Age group 18-80 years. The selection of patient to Age and Sex was random and all patients belonged to ASA grade I \&II. The Mean Age of patients in our study was $55.6 \pm 12.2$ year in group I54.80 \pm 12.80 years in group II. The demographic characteristics of our patients were quite similar with other research investigations and provided us a uniform platform to evenly compare the results obtained.

There was statistically insignificant difference in onset of FICB between control and intervention groups. The analysis of mean VAS score in both groups showed that mean VAS score was significantly more in first group (control) at 30 minutes, Rest of the time there was no statistically significant difference in VAS scores due to effect of spinal anaesthesia in control as well as intervention groups. During patient positioning for spinal anaesthesia $97 \%$ of patients were satisfied and gave satisfactory position for spinal block.

In a study conducted by Kumie F T et al, Efficacy of fascia iliaca compartment nerve block as part of multimodal analgesia after surgery for femoral bone fracture The FICNB group was given $30 \mathrm{ml}$ of $0.25 \%$ bupivacaine at the end of the operation. The time for the first analgesic request was significantly prolonged (417.50 minutes i.e. 6.9 hours vs. 139.25 minutes, $\mathrm{P}=0.000$ ) which is similar to our study ${ }^{[11]}$.

In a study conducted by Lopez S 38 Fascia Iliaca Compartment Block for Femoral Bone Fractures in Pre-hospital Care, The simplified verbal scale (SVS) was 3 (3-4) before the block, 1 (0-2) 10 minutes after the block, and $0(0-1)$ when arriving at the trauma care center $(\mathrm{P}<.05)$. They used $20 \mathrm{ml}$ of lidocaine $1.5 \%$ with epinephrine in their study [12].

Hanna A et al 54 in their study "The Role of Fascia Iliaca Blocks in Hip Fractures: A Prospective Case-Control Study and Feasibility Assessment of a Junior-Doctor-Delivered Service", the pain scores reduced from 8 to 6 in 15 minutes , and to 4 in 2 hours. $0.25 \% 30 \mathrm{ml}$ levobupivacaine was used in their study. In a study conducted by Els Dochez 53 Prehospital administered fascia iliaca compartment block by emergency medical service nurses, The initial median (NRS)-pain score decreased after block performance to a score of 6 (after 10 minutes), 4 (after 20 minutes) and 3 (after 30 minutes). The drugused was $0.3 \mathrm{ml} / \mathrm{kg}$ lidocaine $(10 \mathrm{mg} / \mathrm{ml})$ with adrenaline $5 \mu \mathrm{g} / \mathrm{ml}$, which is comparable with our study ${ }^{[13,14]}$.

Candal couto et al performed FICB in patients with femoral neck fractures waiting for surgery and assessed block efficacy using hip flexion and internal rotation, sitting scale and VAS. They concluded that fascia iliaca blocks can provide significant benefit in the pre-operative period and allow patients to sit up more comfortably while they await surgery. Visual analogue scores improved significantly from 7.2 to 4.6 (S.D. 2.4) at $1 \mathrm{hr}$ post block. The drug used in their study was $15 \mathrm{ml}(0.5 \%)$ levobupivacaine ${ }^{[15]}$.

\section{Conclusion}

FICB using $0.25 \%$ Bupivacaine is a fast and effective method for positioning of patient and post-operative pain relief in patients undergoing surgery for fracture neck of femur under spinal anaesthesia. Moreover FICB can also be used to relieve acute pain in patients of fracture femur in wards so that patients could sit up more comfortably.

\section{Conflict of Interest: None}




\section{References}

1. Ossendorf C, Scheyerer MJ, Wanner GA, Simmen H-P, Werner CM. Treatment of femoral neck fractures in elderly patients over 60 years of age - which is the ideal modality of primary joint replacement? Patient Safety in Surgery. 2010;4:16.

2. Harsoor S. Emerging concepts in postoperative pain management. Indian Journal of Anaesthesia. 2011;55(2):101103.

3. Williams $H$, Paringe $V$, Shenoy $S$, Michaels P, Ramesh B. Standard preoperative analgesia with or without fascia iliaca compartment block for femoral neck fractures. J Orthop Surg (Hong Kong). 2016 Apr;24(1):31-5.

4. Elkhodair S, Mortazavi J, Chester A, Pereira M. Single fascia iliaca compartment block for pain relief in patients with fractured neck of femur in the emergency department: a pilot study. Eur J Emerg Med. 2011 Dec;18(6):340-3.

5. Pinson S. Fascia Iliaca (FICB) block in the emergency department for adultswith neck of femur fractures: A review of the literature. Int Emerg Nurs. 2015Oct;23 (4):323-8.

6. Wells N, Pasero C, Mccaffery M. Improving the Quality of Care through Pain Assessment and Management. Patient Saf Qual An EvidenceBased Handb Nurses Vol 1. 2004;469-86.

7. Cuignet O, Mbuyamba J, Pirson J. The long-term analgesic efficacy of a single shot fascia iliaca compartment block in burn patients undergoing skin-grafting procedures. J Burn Care Rehabil. 2005; 26 (5): 409-15.

8. Capdevila X, Biboulet P, Bouregba M, Barthelet Y, Rubenovitch J, d' A this F. Comparison of the three-in-one and fascia iliaca compartment blocks in adults: clinical and radiographic analysis. Anesth Analg. 1998;86(5):1039-44.
9. Sandby-Thomas M, Sullivan G, Hall JE. A national survey into the perioperative anaesthetic management of patients presenting for surgical correction of a fractured neck of femur. In: Anaesthesia. 2008. p.250-8.

10. Ghimire A, Bhattarai B, Koirala S, Subedi A. Analgesia before Performing Subarachnoid Block in the Sitting Position in Patients with Proximal Femoral Fracture: A Comparison between Fascia Iliaca Block and Femoral Nerve Block. Kathmandu Univ Med J 2015;50(2):152-5.

11. Kumie FT, Gebremedhn EG, Tawuye HY. Effi cacy of fascia iliaca compartment nerve block as part of multimodal analgesia after surgery for femoral bone fracture.. World J Emerg Med 2015;6(2):142-146.

12. Lopez S, Gros T, Bernard N, Plasse C, Capdevila $\mathrm{X}, \mathrm{Ph}$ D. Fascia Iliaca Compartment Block for Femoral Bone Fractures in Prehospital Care. 2003;28(3):203-7.

13. Hanna L, Gulati A, Graham A. The Role of Fascia Iliaca Blocks in Hip Fractures: A Prospective Case-Control Study and Feasibility Assessment of a Junior-DoctorDelivered Service. ISRN Orthopedics 2014.

14. Dochez E, Geffen GJ Van, Bruhn J, Hoogerwerf N, Pas H Van De, Scheffer G. Prehospital administered fascia iliaca compartment block by emergency medical service nurses, a feasibility study Scandinavian Journal of Trauma, Resuscitation and Emergency Medicine 2014, 22:38

15. Candal-couto JJ, Mcvie JL, Haslam N, Innes AR. Pre-operative analgesia for patients with femoral neck fractures using a modified fascia iliaca block technique. 2005; 505-10. 